\title{
Perancangan Ulang Instalasi Pengolahan Air Limbah Domestik dengan Proses Anaerobic Baffled Reactor dan Anaerobic Filter
}

\author{
Habib P. Adi ${ }^{1}$, Mohammad Razif ${ }^{2}$, Atiek Moesriati ${ }^{3}$ \\ 1,2,3 Jurusan Teknik Lingkungan, Fakultas Teknik Sipil dan Perencanaan \\ Institut Teknologi Sepuluh Nopember (ITS) \\ J1. Raya ITS Surabaya 60111 Indonesia \\ e-mail: ${ }^{1}$ habibprasetia@yahoo.com, ${ }^{2}$ razif@its.ac.id, ${ }^{3}$ moesriati@gmail.com
}

\begin{abstract}
Abstrak-Instalasi Pengolahan Air Limbah (IPAL) Tarbiyatul Fallah merupakan IPAL domestik yang melayani Pesantren Tarbiyatul Fallah, namun berhenti beroperasi sejak tahun 2014. Agar manfaat IPAL dapat terus dirasakan, dilakukan perancangan ulang IPAL dengan alternatif Anaerobic Baffled Reactor (ABR) dan Anaerobic Filter (AF). Alternatif IPAL anaerobik yang keunggulan dalam kemudahan penerapan dan biaya operasional yang rendah. Perancangan ulang dimulai dengan mengevaluasi kinerja IPAL yang sudah ada. Hasil evaluasi digunakan untuk mengetahui permasalahan IPAL. Kemudian dilakukan perencanaan aternatif IPAL dengan proses ABR dan AF. Hasil perencanaan adalah berupa DED, BOQ, dan RAB pembangunan dan operasional. Berdasarkan hasil tersebut kemudian dibandingkan kelebihan dan kekurangan dari masingmasing alternatif IPAL. IPAL Tarbiyatul Fallah berhenti beroperasi disebabkan oleh permasalahan bau dan suara bising dari proses aerasi yang meresahkan masyarakat dan biaya operasional yang tinggi. Alternatif IPAL pengganti dapat berupa ABR dengan dimensi $(15,1 \mathrm{~m} \times 1,9 \mathrm{~m} \times 2,3 \mathrm{~m})$ dan AF dengan dimensi (13,75 m x 2,4 m x 2,3 m). Biaya pembangunan untuk ABR sebesar Rp152.969.500 dan AF sebesar Rp175.140.500. Sedangkan biaya operasional ABR sebesar Rp17.012.400 per tahun dan AF sebesar Rp21.345.950 per tahun. ABR memiliki keunggulan dalam hal tingkat penyisihan polutan, waktu tinggal, luas lahan dan biaya pembangunan dan operasional dibanding AF. Sedangkan AF memiliki keunggulan dalam jumlah kompartemen dan kebutuhan beton yang dibanding ABR.
\end{abstract}

Kata Kunci-IPAL Tarbiyatul Fallah, ABR, AF, Perancangan Ulang.

\section{PENDAHULUAN}

$\mathrm{P}$ ENYEDIAAN Instalasi Pengolahan Air Limbah (IPAL) bertujuan untuk meningkatkan kualitas layanan sanitasi masyarakat yang dilayani maupun masyarakat di sekitarnya. Keberadaan IPAL Tarbiyatul Fallah telah mampu mengatasi pencemaran air tanah yang telah terjadi selama bertahun-tahun di RT.1 RW.1 Kelurahan Sukorejo Kota Blitar. Namun, sejak tahun 2014, berdasarkan hasil pemetaan IPAL yang dilakukan oleh Bappeda Kota Blitar (2015) ${ }^{[1]}$, IPAL yang melayani 96 penduduk ini telah berhenti beroperasi. Adanya keresahan masyarakat akibat permasalahan bau dan suara bising dari operasional IPAL menyebabkan IPAL berhenti beroperasi. Biaya operasional yang tinggi juga menjadi penyebab lain berhenti beroperasinya IPAL. Agar manfaat keberadaan IPAL dapat terus dirasakan, maka dilakukan perancangan ulang IPAL.

IPAL domestik dikatakan berfungsi dengan baik apabila efluen IPAL telah memenuhi baku mutu. Baku mutu yang berlaku untuk limbah domestik meliputi parameter pencemar organik sulit terdegradasi secara biologis (COD), pencemar organik mudah terdegradasi secara biologis (BOD), padatan tersuspensi (TSS), derajat keasaman (pH) dan minyak dan lemak. Baku mutu limbah domestik untuk Kota Blitar mengacu pada Peraturan Gubernur Jawa Timur No.72 Tahun 2013 tentang Baku Mutu Air Limbah bagi Industri dan/atau Kegiatan Usaha Lainnya.

Perancangan ulang dilakukan untuk memberikan alternatif IPAL baru dengan mengevaluasi IPAL yang sudah ada. Aspek yang akan dikaji meliputi aspek teknis dan finansial. Aspek teknis akan membahas desain tiap alternatif IPAL yang dapat memenuhi bakumutu air limbah dengan meminimalkan luas lahan yang diperlukan. Aspek finansial akan membahas rencana anggaran biaya ( $\mathrm{RAB}$ ) untuk tahap pembangunan dan pengoperasian. Kemudian dilakukan analisis perbandingan kelebihan dan kekurangan dari kedua alternatif baik untuk tahap pembangunannya maupun tahap operasinya.

Anaerobic Baffled Reactor (ABR) dan Anaerobic Filter (AF) dipilih sebagai alternatif IPAL pengganti karena memiliki efisiensi penyisihan polutan organik yang tinggi. Selain itu, ABR dan AF juga cocok digunakan untuk mengolah air limbah domestic (Sasse, 1998) ${ }^{[2]}$. IPAL dengan proses anaerobik tidak memerlukan suplai oksigen dalam proses pengolahannya, sehingga tidak memerlukan aerator dan dapat dibangun tertutup (Qasim, 1985) ${ }^{[3]}$.

\section{METODE}

\section{A. Persiapan Perencanaan}

Mengumpulkan data-data primer dan sekunder. Tujuan dari kegiatan ini adalah mendapatkan data-data yang relevan untuk digunakan sebagai kriteria dan bahan pertimbangan dalam perencanaan. Sumber data-data tersebut berasal dari Instansi Pemerintah Kota Blitar yang membawahi IPAL Domestik dan juga pustaka-pustaka yang menunjang. Data primer yang 
didapatkan berupa luas lahan tersedia dan kuantitas air limbah yang diperoleh dengan wawancara dan kuesioner. Sedangkan data sekunder yang didapatkan berupa data pemakaian air bersih, monografi penduduk serta kualitas dan kuantitas air limbah domestik..

\section{B. Perhitungan Dimensi Unit IPAL}

Kegiatan ini bertujuan untuk mengolah data-data yang telah didapatkan dengan menggunakan rumusan-rumusan yang ada di dalam perancangan ABR dan AF. Langkah-langkah perhitungan IPAL ini disajikan pada Gambar 1 dan Gambar 2.

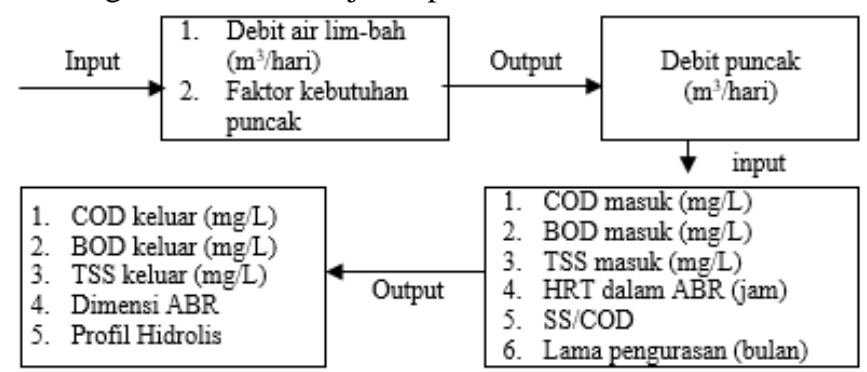

Gambar 1. Bagan Alir Perhitungan Dimensi Anaerobic Baffled Reactor

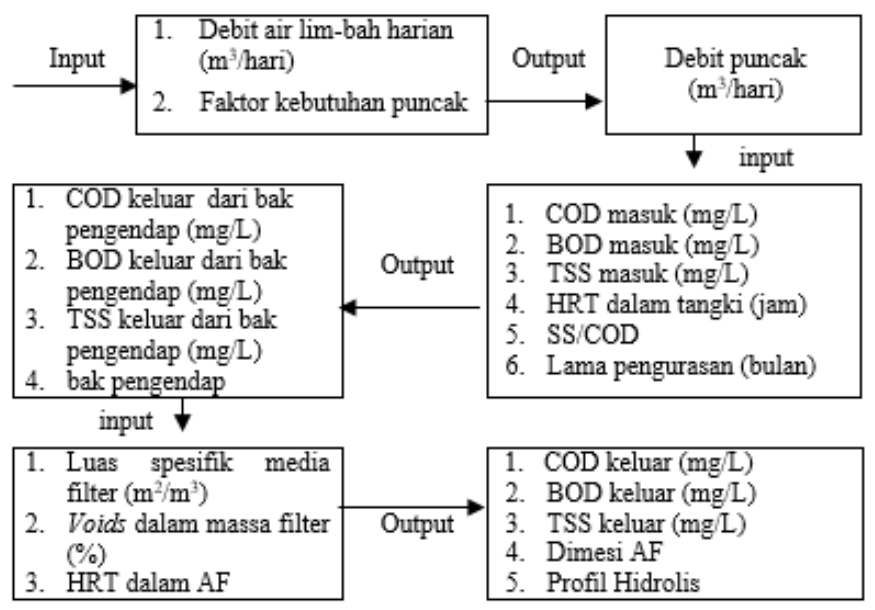

Gambar 2. Bagan Alir Perhitungan Dimensi Anaerobic Filter

\section{Perencanaan Unit IPAL}

Hasil perhitungan dimensi AF dan ABR kemudian dibuat gambar secara detail atau Detail Engineering Design (DED). Kemudian dihitung estimasi biaya yang akan dianggarkan untuk tahap pembangunan dan operasional \& perawatan dari DED yang telah digambar.

\section{HASIL DAN PEMBAHASAN}

\section{A. Analisis Hasil Survei}

Survei dilakukan dengan metode random sampling. Survei dilakukan untuk mendapatkan debit air bersih dan faktor penggunaan air bersih. Faktor pengggunaan digunakan untuk menentukan faktor puncak $\left(f_{\text {peak }}\right)$ yang merupakan nilai tertinggi dari faktor penggunaan, yakni sebesar 2,9. Perolehan faktor penggunaan disajikan pada Gambar 3 .

Perhitungan kebutuhan air bersih dilakukan dengan 2 (dua) cara, pertama berdasarkan frekuensi pemompaan, kedua berdasarkan selisih debit masuk dan keluar elevated reservoir. Diperoleh debit air bersih terbesar adalah 22,98 $\mathrm{m}^{3} /$ hari.

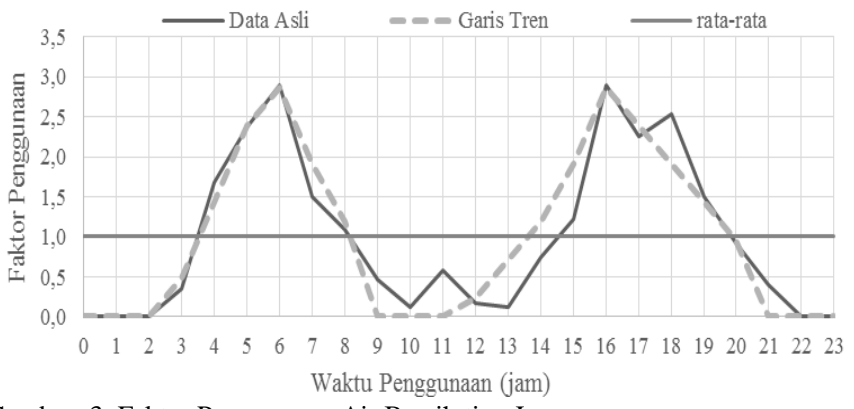

Gambar 3. Faktor Penggunaan Air Bersih tiap Jam

\section{B. Debit dan Karakteristik Air Limbah}

Perhitungan debit air limbah dilakukan dengan 2 (dua) cara, pertama dengan meng-asumsikan $80 \%$ debit air bersih menjadi air limbah, kedua dengan menghitung produksi air limbah berdasarkan jenis dan frekuensi kegiatan (Tabel 1). Diperoleh debit air limbah dengan cara pertama sebesar $18,38 \mathrm{~m}^{3} / \mathrm{hari}$ dan cara kedua sebesar 21,67 $\mathrm{m}^{3} /$ hari. Dipilih debit air limbah terbesar untuk perencanaan ini.

Tabel 1.

Debit Air Limbah Berdasarkan Jenis dan Frekuensi Kegiatan

\begin{tabular}{|c|c|c|c|c|}
\hline Kegiatan & $\begin{array}{c}\text { Kebutuhan } \\
\text { Air bersih } \\
\text { (L/hari) }\end{array}$ & $\begin{array}{c}\text { Frek. } \\
\text { Harian }\end{array}$ & $\begin{array}{c}\text { Produksi Debit } \\
\text { Air Limbah } \\
\text { (L/O.H) }\end{array}$ & $\begin{array}{c}\text { Debit Air } \\
\text { Limbah } \\
\left(\mathrm{m}^{3} / \mathrm{hari}\right)\end{array}$ \\
\hline Mandi & 45,53 & 2,1 & 95,61 & 9,18 \\
\hline Mencuci & 86,66 & 0,34 & 29,71 & 2,85 \\
\hline Memasak & 14,44 & 0,4 & 5,78 & 0,55 \\
\hline $\mathrm{BAB}$ & 38,62 & 1,1 & 42,5 & 4,08 \\
\hline BAK & 20,1 & 2,6 & 52,25 & 5,02 \\
\hline \multicolumn{4}{|c|}{ Jumlah } & 21,67 \\
\hline
\end{tabular}

Karakteristik air limbah dihitung berdasarkan beban pencemar limbah domestik perkapita di Indonesia, dimana beban pencemar limbah domestik untuk BOD dan COD masing-masing sebesar $25 \mathrm{gr} / \mathrm{kap}$.hari dan 57 gr/kap.hari (Salim, 2002) $)^{[4]}$. Sedangkan karakteristik TSS dihitung berdasarkan rasio TSS/COD sebesar 0,42 (Sasse, 2009). Diperoleh konsentrasi pencemar air limbah untuk parameter COD, BOD, dan TSS masing-masing adalah sebesar 252,44 $\mathrm{mg} / \mathrm{L} ; 110,72 \mathrm{mg} / \mathrm{L}$ dan 106,03 mg/L. Berdasarkan Peraturan Gubernur Jawa Timur No.72 Tahun 2013 tentang Baku Mutu untuk Air Limbah Domestik maka masing-masing parameter tersebut belum memenuhi bakumutu, sehingga perlu pengolahan untuk memenuhi baku mutu yang berlaku.

\section{Evaluasi IPAL Eksisting}

Evaluasi dilakukan pada 2 (dua) parameter, yakni kinerja IPAL dan kondisi fisik IPAL. Evaluasi kinerja IPAL dinilai dengan menghitung kemampuan penyisihan pencemar oleh IPAL eksisting (Gambar 4). Unit tangki septik merupakan satu-satunya unit dari IPAL eksisitng yang masih beroperasi, Unit tangki septik berdimensi $2,5 \mathrm{~m} \times 3 \mathrm{~m} \times 4 \mathrm{~m}$ untuk kompartemen pertama dan $4 \mathrm{~m} \times 3 \mathrm{~m} \times 2 \mathrm{~m}$ untuk kompartemen kedua. Hasil evaluasi menujukkan bahwa unit tangki septikmemenuhi kriteria desain sebagai septik tank. Waktu tinggal hidrolik (HRT) unit septik tank adalah 51,02 jam. Efisiensi penyisihan polutan oleh tangki septik untuk parameter COD, BOD, dan TSS adalah masing-masing sebesar 
$39 \%$, 41\%, dan 16\%. Sehingga effluen IPAL eksisting tidak memenuhi baku mutu yang berlaku. Pengolahan secara anaerob telah berlangsung pada unit tangki septik dengan HRT lebih dari 24 jam (Sasse, 2009) ${ }^{[4]}$. Pengolahan anaerob diketahui akan menghasilkan gas metana dan gas hidrogen sulfida yang dapat menimbulkan bau tidak sedap (Mara, 2004) $)^{[5]}$. Gas metana yang terbentuk adalah sebesar 530 liter/hari (Gambar 4). Pemanfaatan unit tangki septik untuk alternatif IPAL baru tidak dapat dilakukan karena HRT tidak memenuhi kriteria desain.

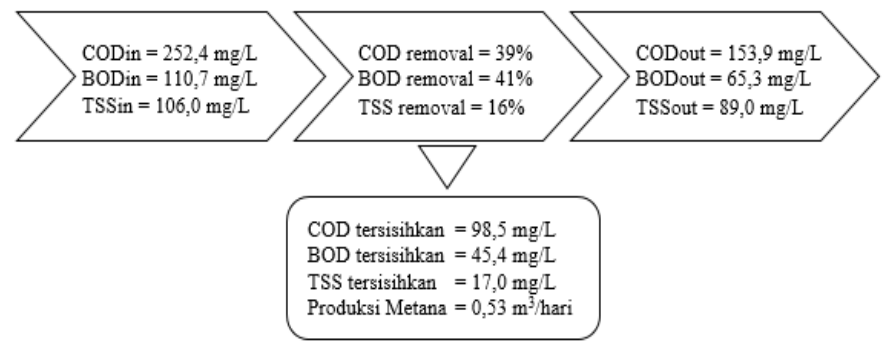

Gambar 4. Kesetimbangan Massa (Mass Balance) IPAL Tarbiyatul Fallah

Evaluasi kondisi fisik dinilai berdasarkan kesesuaian ukuran bangunan dengan DED dan kondisi fisik bangunan. Unit IPAL eksisting merupakan IPAL proses aerobik yang terdiri dari unit tangki septik sebagai settler, aerasi, clarifier, biofilter, dan kolam indikator. Unit aerasi menggunakan aerator mekanik, penggunaan aerator mekanik inilah yang menyebabkan suara bisisng ketika beroperasi. Kondisi fisik bangunan masih baik namun tidak terawat, sehingga terdapat genangan air.

\section{Alternatif Bangunan Pengolah Air Limbah}

Perancangan ulang ini memebandingkan 2 (dua) alternatif pengolahan yang ditampilkan pada Gambar 5 dan Gambar 6. Warna box putih pada gambar tersebut menunjukkan sumber air limbah. Warna ungu menunjukkan unit sudah terbangun dan masih dapat digunakan. Warna coklat menunjukkan unit baru yang akan direncanakan.

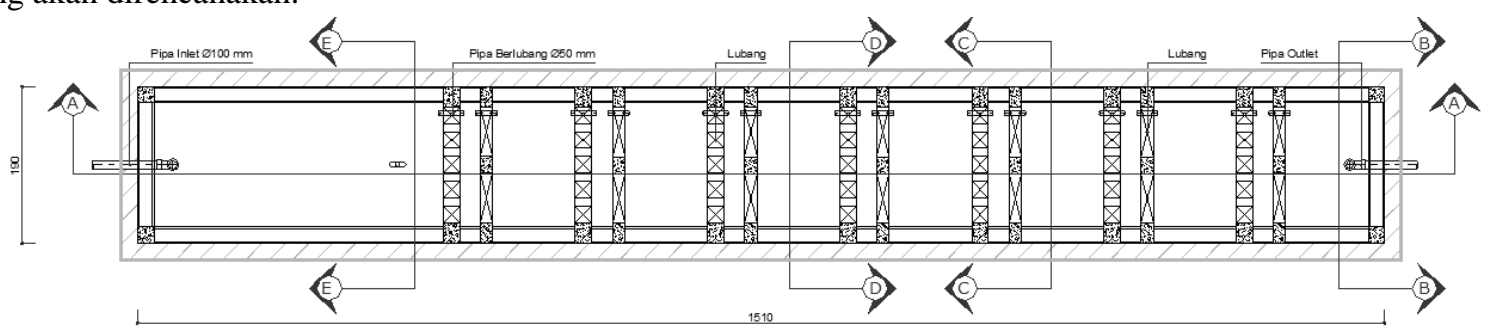

Gambar 7. Denah Anaerobic Baffled Reactor (ABR)

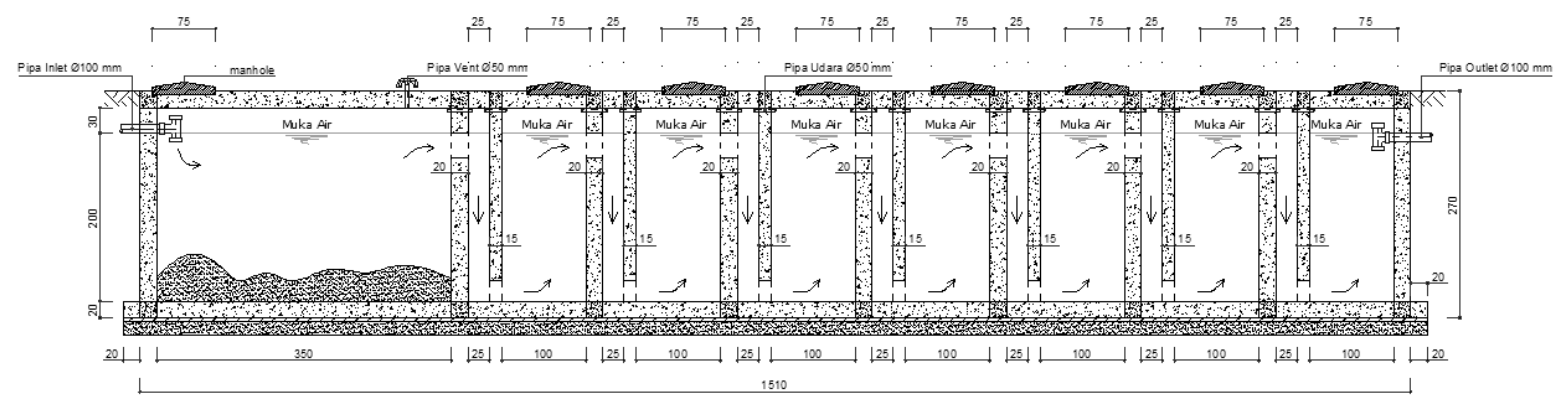

Gambar 8. Potongan Melintang (A-A) Anaerobic Baffled Reactor (ABR)

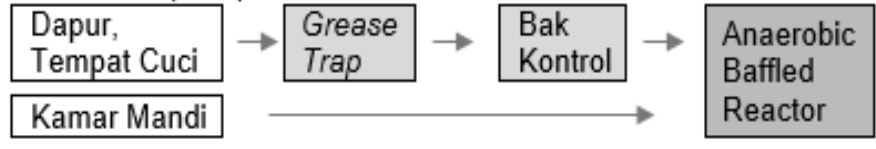

Gambar 5. Bagan Alir Alternatif IPAL 1.

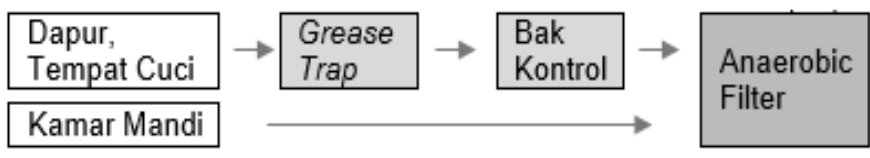

Gambar 6. Bagan Alir Alternatif IPAL 2.

\section{E. Hasil Perhitungan Dimensi dan Gambar DED}

Perhitungan dimensi IPAL digunakan sebagai dasar untuk menggambar Detail Engineering Design (DED) IPAL. Perhitungan dimensi IPAL memperhatikan kriteria-kriteria perencanaan yang didapatkan dari studi pustaka.

\section{Anaerobic Baffled Reactor (ABR)}

Unit pengolahan biologis pada alternatif 1 adalah ABR. ABR merupakan jenis reaktor anaerob laju tinggi yang terdiri dari beberapa kompartemen bervolume sama. Antar tiap kompartemen ABR dipisahkan oleh hanging dan standing baffle secara selang-seling yang berfungsi memaksa cairan mengalir ke atas dan ke bawah pada tiap kompartemen untuk meningkatkan kontak antara air limbah dan mikroorganisme dalam selimut lumpur pada tiap dasar kompartemen (Hudson, $2010)^{[6]}$. Hasil perhitungan didapat dimensi ABR yaitu sebesar (3,5m x 1,5m x 2m) untuk bagian bak pengendap dan (1m x $1,5 \mathrm{~m} \times 2 \mathrm{~m}$ ) untuk tiap kompartemen dengan jumlah kompartemen sebanyak 7 buah. HRT efektif ABR adalah 29,03 jam.

Kesetimbangan massa (mass balance) pada unit ABR ditampilkan pada Gambar 9. Diketahui bahwa dari Gambar 9 efisiensi penyisihan polutan pada unit ABR untuk parameter COD, BOD dan TSS masing-masing adalah 86\%, 92\% dan $36 \%$. Seluruh parameter effluen memenuhi baku mutu. 


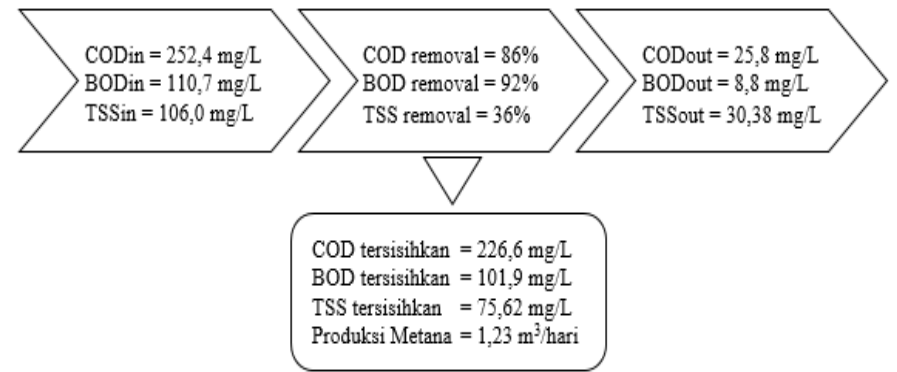

Gambar 9. Kesetimbangan Massa (Mass Balance) IPAL Alternatif 1

\section{Anaerobic Filter (AF)}

Unit pengolahan biologis pada alternatif 2 adalah AF. AF merupakan sebuah reaktor anaerob, dimana air limbah mengalir melewati mikroorganisme di dalam reaktor yang dibedakan menjadi tiga jenis yakni: (1) lapisan biofilm tipis yang menempel pada permukaan media filter, (2) mikroorganisme yang tersebar pada celah media filter dan (3) Flok-flok atau gumpalan di dasar kompartemen, yang berada di bawah media filter (von Sperling, 2005) ${ }^{[7]}$. Hasil perhitungan didapat dimensi AF yaitu sebesar $(3,5 \mathrm{~m} \times 2 \mathrm{~m} \times 2$ $\mathrm{m})$ untuk bagian bak pengendap dan ( $2 \mathrm{~m} \times 2 \mathrm{~m} \times 2 \mathrm{~m})$ untuk tiap kompartemen dengan jumlah kopartemen sebanyak 4 buah. Media filter yang digunakan adalah media filter sarang tawon dengan voids sebesar 98\% dan luas spesifik permukaan media filter sebesar $200 \mathrm{~m}^{2} / \mathrm{m}^{3}$ (Said, 2007) ${ }^{[8]}$. HRT efektif AF adalah 34,46 jam.

Kesetimbangan massa (mass balance) pada unit $\mathrm{AF}$ ditampilkan pada Gambar 12. Diketahui bahwa dari Gambar 12 efisiensi penyisihan polutan pada unit AF untuk parameter COD, BOD dan TSS masing-masing adalah $80 \%$, 87\% dan $34 \%$. Seluruh parameter effluen memenuhi baku mutu.

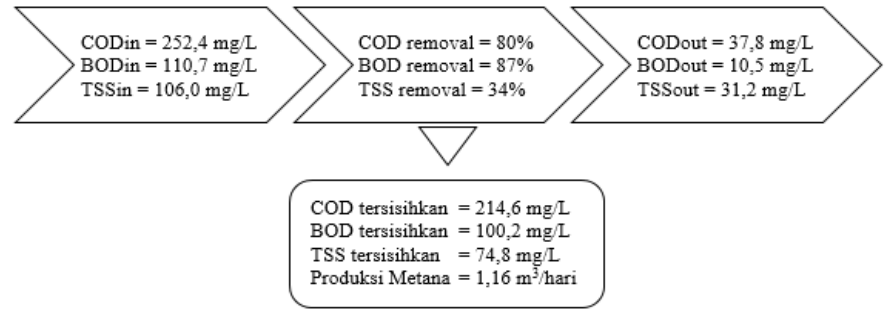

Gambar 12. Kesetimbangan Massa (Mass Balance) IPAL Alternatif 2

\section{F. Hasil Perhitungan RAB Alternatif IPAL}

Rencana anggaran biaya (RAB) digunakan untuk menentukan jumlah investasi yang diperlukan untuk pembangunan dan operasional IPAL. RAB dihitung berdasarkan volume pekerjaan dan Harga Satuan Pokok Kegiatan (HSPK) Kota Blitar 2016 dikalikan volume pekerjaan. Hasil perhitungan RAB ini akan dijadikan sebagai dasar untuk pemilihan alternatif IPAL yang lebih baik dalam aspek finansial.

Tabel 2

RAB Pembangunan AF

\begin{tabular}{llc}
\hline \hline No & Uraian Pekerjaan & Jumlah Harga \\
\hline 1. & Pekerjaan Persiapan & Rp9.890.442 \\
2. & Pekerjaan Beton dan Pasangan & Rp110.103.262 \\
3. & Pekerjaan Pengadaan dan & Rp2.483.200 \\
4. & Pekerjaan Pengadaan dan & Pemasangan Perlengkapan Lainnya \\
5. & Pekerjaan Finishing & Rp52.107.637 \\
Total & Rp175.140.500 \\
\hline \hline
\end{tabular}

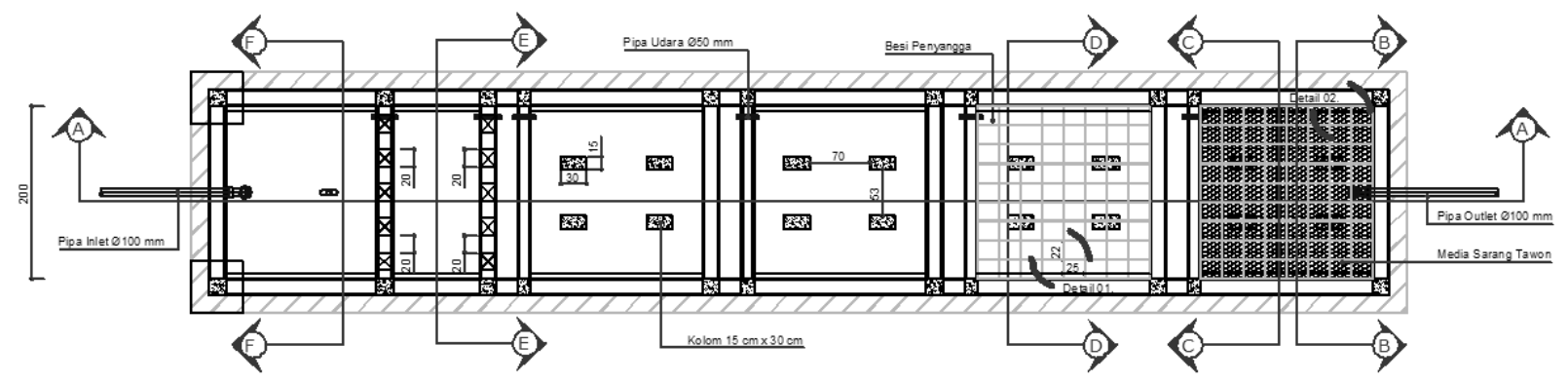

Gambar 10. Denah Anaerobic Filter (AF)

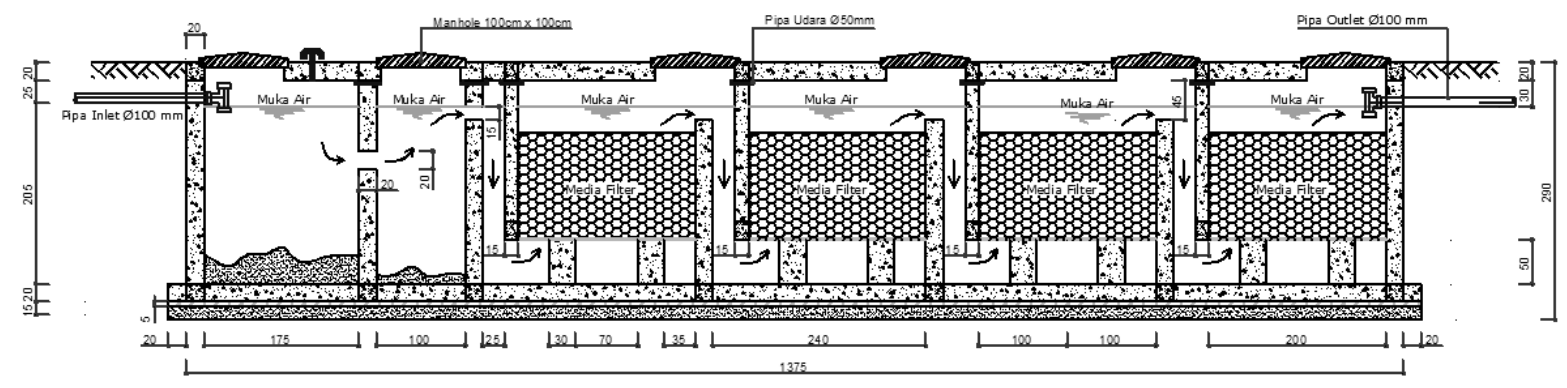

Gambar 11. Denah Anaerobic Filter (AF) 
Tabel 3.

RAB Operasional dan Perawatan AF

\begin{tabular}{|c|c|c|}
\hline No & Uraian Pekerjaan & Biaya/ Tahun \\
\hline 1. & Upah Operator & Rp16.776.000 \\
\hline 2. & Biostarter Startup & Rp41.250 \\
\hline 3. & Pengurasan & Rp.200.000 \\
\hline \multirow[t]{2}{*}{4.} & Penggantian Media Filter & Rp4.328.700 \\
\hline & Total & Rp21.345.950 \\
\hline
\end{tabular}

Tabel 4.

RAB Pembangunan ABR

\begin{tabular}{clr}
\hline \hline No & \multicolumn{1}{c}{ Uraian Pekerjaan } & \multicolumn{1}{c}{ Jumlah Harga } \\
\hline 1. & Pekerjaan Persiapan & Rp9.890.442 \\
2. & Pekerjaan Beton dan Pasangan & Rp110.103.262 \\
3. & Pekerjaan Pengadaan dan & Rp2.483.200 \\
& Pemasangan Perpipaan dan Asesoris & Rp555.901 \\
4. & Pekerjaan Finishing & Total \\
& & Rp175.140.500 \\
\hline \hline
\end{tabular}

Tabel 5.

RAB Operasional dan Perawatan ABR

\begin{tabular}{|c|c|c|}
\hline No & Uraian Pekerjaan & Biaya/ Tahun \\
\hline 1. & Upah Operator & Rp16.776.000 \\
\hline 2. & Biostarter Startup & Rp36.400 \\
\hline \multirow[t]{2}{*}{3.} & Pengurasan & Rp200.000 \\
\hline & Total & Rp17.012.400 \\
\hline
\end{tabular}

Diketahui dari Tabel 2 dan Tabel 3 bahwa RAB pembangunan untuk alternatif 1 senilai Rp152.969.500 lebih rendah dari alternatif 2 senilai Rp175.140.500. Sejalan dengan RAB Operasional, yang mana berdasarkan Tabel 4 dan Tabel 5 diketahui bahwa RAB operasional untuk alternatif 1 senilai Rp17.012.400/tahun lebih rendah dari alternatif 2 senilai Rp21.345.950/tahun.

\section{G. Hasil Perbandingan Alternatif IPAL}

Telah dilakukan pembahasan aspek teknis dan aspek finansial untuk setiap alternatif IPAL. Berdasarkan kedua aspek tersebut, dapat dilakukan perbandingan kelebihan dan kekurangan alternatif IPAL sebagai berikut:

1) Alternatif 1 memiliki unggul dalam hal penyisihan polutan yang lebih tinggi, luas lahan yang lebih kecil, waktu tinggal yang lebih singkat, biaya pembangunan yang lebih rendah dan biaya operasional yang lebih rendah..

2) Alternatif 2 unggul dalam hal jumlah kompartemen yang lebih sedikit dan kebutuhan beton yang lebih sedikit.

\section{KESIMPULAN}

Alternatif 1 dengan teknologi ABR memiliki keunggulan lebih banyak dibandingkan alternatif 2. ABR unggul dalam aspek teknis dengan efisiensi penyisihan polutan yang lebih baik. ABR juga unggul dalam aspek finansial dengan biaya pembangunan dan operasional dan perawatan yang lebih rendah. Sehingga, ABR lebih layak dipilih sebagai alternatif pengganti IPAL Tarbiyatul Fallah.

\section{UCAPAN TERIMA KASIH}

Penulis mengucapkan terima kasih kepada Dinas Lingkungan Hidup Kota Blitar dan Dinas Pekerjaan Umum dan Perumahan Rakyat Kota Blitar yang telah bersedia memberikan data-data mengenai IPAL Tarbiyatul Fallah.

\section{DAFTAR PUSTAKA}

[1] Bappeda Kota Blitar. 2015. Pemetaan IPAL (Instalasi Pengolahan Air Limbah) Komunal Kota Blitar Tahun 2015. Pemerintah Kota Blitar.

[2] Sasse. 1998. DEWATS: Decentralized Wastewater Treatment in Developing Countries. Bremen: BORDA.

[3] Qasim, S.R. 1985. Wastewater Treatment Plants: Planning, Design and Operation, Second Edition. New York: CRC Press.

[4] Sasse. 2009. Decentralised Wastewater Treatment Systems (DEWATS) and Sanitation in Developing Countries - Practical Guide. Bremen: BORDA

[5] Mara, Duncan. 2004. Domestic Wastewater Treatment in Developing Countries. London: Earthscan.

[6] Hudson, Kerri. 2010. "Operational Performance of the Anaerobic Baffled Reactor Used to Treat Wastewater from a Peri Urban Community". Research for Master of Science University of the Witwatersrand Johannesburg - South Africa.

[7] von Sperling, Marcos. 2005. Biological wastewater Treatment in Warm Climate Regions, Vol.one. London: IWA Publishing.

[8] Said, Nusa I. 2015. Proses Biologi. Tersedia di: http://www.kelair.bppt.go.id/Publikasi/Buku99LimbahCairIndustri/013 biologi.pdf $>$. Diakses pada tanggal 5-1-2016 Pukul 12.00 WIB. 